\title{
REFLETINDO O PROCESSO DE TRABALHO NO PERÍODO PERIOPERATÓRIO A PARTIR DAS NECESSIDADES DO PACIENTE
}

\section{Reflecting about the work process in the perioperative's period from the patient's needs}

\author{
Nathália Romeu de Mazzi \\ Universidade do Oeste Paulista - UNOESTE - Presidente Prudente (SP) - Brasil
}

Silvia Franco da Rocha Tonhom

Faculdade de Medicina de Marília - FAMEMA - Marilia (SP) - Brasil

\section{RESUMO}

Objetivo: Analisar as necessidades dos pacientes no momento perioperatório e, a partir de tais necessidades, compreender o processo de trabalho promovido pela equipe de saúde nesse período. Métodos: Na primeira etapa da pesquisa, foram realizadas 26 entrevistas semiestruturadas com pacientes submetidos a cirurgias eletivas, entre fevereiro e maio de 2016, em um hospital de clínicas de um município do interior do estado de São Paulo, sendo analisadas à luz do discurso do sujeito coletivo. Na segunda etapa, os discursos obtidos foram utilizados como disparadores de discussão em quatro grupos focais com a equipe de saúde, entre setembro e novembro de 2016, analisados segundo a técnica hermenêutica-dialética. Resultados: Os pacientes relataram ter recebido informações superficiais sobre o cuidado e apresentaram pouca autonomia nesse processo, aludindo a família e espiritualidade como apoio para o enfrentamento do momento. A equipe de saúde, por sua vez, mencionaram a comunicação ineficaz como aspecto que dificulta a assistência integral e interdisciplinar, apontando a necessidade de aproximação entre os profissionais a fim de articular as ações visando a qualidade da assistência. Conclusão: A garantia e consolidação de espaços de educação permanente nos serviços de saúde possibilita uma assistência centrada no paciente e com vistas às práticas colaborativas.

Descritores: Assistência Perioperatória; Educação em Saúde; Integralidade em Saúde; Comunicação; Relações Interprofissionais.

\section{ABSTRACT}

Objective: Were to analyse the patients' needs at the perioperative moment and, from such needs, to understand the work process promoted by the health team during this period. Methods: In the first stage of the research, 26 semistructured interviews were conducted with patients submitted to elective surgeries between February and May 2016, in a hospital center (in Portuguese, called hospital of clinics) of a city in the interior of the state of São Paulo, and analysed regarding the discourse of the collective subject. In the second stage, the speeches were used as discussion triggers in four focus groups with the health team, between September and November, 2016, analysed according to the hermeneutic-dialectic technique. Results: The patients reported having received superficial information about the care and presented little autonomy in this process, alluding to the family and spirituality as support to face the moment. The health team, on the other hand, mentioned ineffective communication as an aspect that hinders comprehensive and interdisciplinary care, pointing out the need for professionals to approach in order to articulate actions aimed at quality of care. Conclusion: It is observed the guarantee and consolidation of spaces of permanent education in the health services allows a patient-centered assistance and with a view to the collaborative practices.

Descriptors: Perioperative Care; Health Education; Integrality in Health; Communication; Interprofessional Relations. 


\section{INTRODUÇÃO}

O momento perioperatório é um período que pode provocar sentimentos de insegurança e ansiedade para o paciente, visto o surgimento de medo relacionado ao processo cirúrgico, a possíveis deformações ou complicações e à perda de autonomia, mesmo que de maneira momentânea, provocando estresse e podendo comprometer a sua recuperação e promoção de saúde. Por esses fatores, buscando diminuir as repercussões negativas do estresse, é essencial que o paciente compreenda a assistência realizada, recebendo informações individualizadas sobre todo o processo de cuidado ${ }^{(1,2)}$.

Nesse contexto, a educação em saúde contribui para a construção da consciência crítica das pessoas a respeito de sua saúde e para a busca de autonomia. Entretanto, é necessário que esse processo entre profissional e paciente ocorra de maneira dialógica, superando o modelo tradicional impositivo que pouco contribui para o empoderamento do paciente e cuidado integral, bem como para a compreensão do momento vivido(3).

Todavia, nas práticas assistenciais em âmbito hospitalar ainda há dificuldade em operacionalizar o trabalho de modo a superar a educação em saúde tradicional, uma vez que essa abordagem muitas vezes é realizada de modo pouco sistematizado, sem que seja respeitadas as individualidades. Tal acontece devido às ações de saúde ainda estarem arraigadas em um modelo reducionista, organizado por especialidade e enfatizando procedimentos. Por essas limitações, é importante que a equipe possa planejar as ações educativas e priorizá-las em todos os momentos do cuidado no cotidiano de trabalho, vislumbrando uma assistência ampliada ${ }^{(1,4)}$.

Para tanto, no período perioperatório, a educação em saúde dialógica, iniciada desde o momento em que é tomada a decisão de realizar a cirurgia, deve visar não somente a recuperação física e mental do paciente, mas também a promoção de sua saúde, que extrapola o cuidado hospitalar. O profissional de saúde deve construir com o paciente todos os aspectos do seu cuidado em cada um dos momentos, a saber: motivo da cirurgia, tipo de procedimento cirúrgico, repercussões, expectativas, deambulação, nutrição, dor, curativo, tempo de internação e o período pós-alta hospitalar ${ }^{(5)}$.

Assim, para singularizar a assistência, devem-se ultrapassar os limites das atividades instrumentais e de gerenciamento, identificando as reais necessidades do paciente, especialmente aquelas que são implícitas, sendo papel de toda a equipe esclarecer dúvidas, promover educação em saúde e construir o cuidado nesse momento tão delicado. A assistência estará pautada na integralidade, quando os diferentes saberes contribuírem de maneira articulada para um cuidado seguro ${ }^{(6-8)}$.

A experiência e as expectativas dos paciente no perioperatório fornecem subsídios para ações educativas dialógicas e assistência integral, viabilizando sua autonomia no cuidado, estabelecimento de vínculo com a equipe, acesso e uso adequado das tecnologias em saúde, bem como boas condições de vida. A partir dessa perspectiva, torna-se primordial a reorganização dos processos de trabalho em saúde, promovendo um deslocamento do processo assistencial centrado em procedimentos fragmentados para processos que tenham como eixo norteador a tecnologia leve, dando enfoque às relações humanas e à comunicação, considerando os conceitos de acolhimento, responsabilização, vinculação e assistência centrada ao paciente ${ }^{(9-12)}$.

A reflexão a respeito da correlação do cuidado perioperatório com o processo de trabalho e gestão apresenta-se como movimento essencial nas transformações das práticas assistenciais. Sob essa ótica, a Educação Permanente em Saúde (EPS), uma estratégia problematizadora de gestão do Sistema Único de Saúde, apresenta-se como ferramenta importante para o aprimoramento dos serviços prestados, tornando-se extremamente relevante para o trabalho interprofissional, possibilitando reflexões sobre novos modelos assistenciais, assentados nos princípios da integralidade do cuidado e novos olhares e perspectivas para a organização da assistência à saúde, segundo as necessidades do paciente ${ }^{(13,14)}$.

Considerando a necessária relação entre as interfaces educação em saúde hospitalar, interdisciplinaridade e cuidados ao paciente cirúrgico, o presente estudo pode proporcionar importantes reflexões sobre o tema, contribuindo para o aprimoramento do serviço de saúde e da qualidade da assistência no perioperatório, no sentido da assistência ampliada, incluindo a promoção de saúde, a humanização e o trabalho colaborativo. Desse modo, a pesquisa teve como objetivos analisar as necessidades dos pacientes no momento perioperatório e, a partir de tais necessidades, compreender o processo de trabalho promovido pela equipe de saúde nesse período(15).

\section{MÉTODOS}

A pesquisa orienta-se na abordagem qualitativa, sendo de natureza descritivo-exploratória, uma vez que se trabalhou com o universo de significados que corresponde a um espaço mais profundo dos processos ${ }^{(16)}$. Sua 
realização ocorreu no Complexo assistencial de uma faculdade de medicina e enfermagem, de um município do interior do Estado de São Paulo, nos setores de internação da Unidade III do Hospital das Clínicas (HCIII). O HCIII é uma das três unidades que compõe o complexo assistencial da referida faculdade, composto ainda pela Unidade Materno Infantil ( $\mathrm{HC} \mathrm{II)} \mathrm{e} \mathrm{pela} \mathrm{Unidade} \mathrm{Clínico-Cirúrgica} \mathrm{I} \mathrm{(} \mathrm{HC} \mathrm{I}$ ).

O HCIII desenvolve ações de cuidado individual e coletivo, nas áreas de Atenção à Saúde Mental e ClínicoCirúrgica para regime de internação e Oftalmologia para regime ambulatorial. Os setores de internação para Atenção Clínico-Cirúrgica do HCIII dirigem-se à média complexidade e curta permanência para adultos e idosos, principalmente em áreas pré-operatória e pós-operatória de cirurgias eletivas. Devido a essa organização, a Unidade III do HC foi escolhida como cenário do estudo. A proposta de trabalho do serviço pauta-se na integralidade, humanização e gestão compartilhada em saúde.

O estudo foi dividido em duas fases, compondo-se de uma abordagem a pacientes e outra a equipe de saúde. Em um primeiro momento, entre os meses de fevereiro e maio de 2016 , foram realizadas entrevistas a pacientes em situação pós-operatória de cirurgias eletivas, com base em um roteiro semi-estruturado, previamente testado em estudo piloto, para captar as percepções/reflexões/sentimentos dos pacientes com relação ao momento vivenciado, incluindo procedimento cirúrgico, orientações, processo de recuperação e alta hospitalar(16).

O grupo de estudo, definido por meio da técnica de saturação, constituiu-se de 26 participantes e a média de duração das entrevistas foi de 15 minutos, aproximadamente. Os critérios de inclusão para ser participante nesse estudo, por sua vez, foram as seguintes: o paciente encontrar-se em pós-operatório de cirurgia eletiva, com idade acima de 18 anos e estar em condições de responder por si mesmo, concordando e assinando o Termo de Consentimento Livre e Esclarecido (TCLE) $)^{(17)}$.

Todas as entrevistas foram gravadas, transcritas na íntegra, concomitantemente à sua realização, e analisadas utilizando-se a Técnica do Discurso do Sujeito Coletivo (DSC), pautada na Teoria das Representações Sociais, introduzida pr Serge Moscovici, na qual a opinião dos entrevistados é representada por meio de um único discurso, mas sem descaracterizar a natureza qualitativa de cada depoimento. Os discursos foram construídos a partir da identificação das expressões-chave e das ideias centrais ${ }^{(18,19)}$.

A Teoria das Representações Sociais (TRS) proposta Moscovici, que por sua vez engloba a Teoria das Representações Coletivas de Durkheim, pressupõe uma dinâmica entre o conhecimento de senso comum e o conhecimento científico, proporcionando um olhar aprofundado acerca de uma dada coletividade, representada nesse estudo pelos pacientes que vivenciam o perioperatório ${ }^{(19)}$.

Já na segunda etapa, os resultados obtidos nas entrevistas com os pacientes foram utilizados como disparador em grupos focais, entendendo ser essa técnica um espaço privilegiado para discussão dialética, para colaboração na promoção de reflexão com as equipes de saúde, sobre o processo de trabalho na assistência perioperatória, incluindo o cuidado envolvido nesses atendimentos, pautado nos preceitos problematizadores e transformadores da Educação Permanente ${ }^{(14-16)}$.

O disparador utilizado foi um discurso, redigido em primeira pessoa, construído a partir da fusão dos DSC, da primeira etapa da pesquisa. Após a leitura do disparador, os participantes eram convidados a discorrer sobre o discurso lido e relacioná-lo com sua prática no cotidiano de trabalho. Sendo assim, os critérios de inclusão dos participantes, na segunda fase, foram os seguintes: ser integrante da equipe de saúde que presta assistência direta e indireta ao paciente, no período de realização da pesquisa, aceitando e assinando o Termo de Consentimento Livre e Esclarecido.

Realizaram-se quatro grupos focais, no período de setembro a novembro de 2016 , com as equipes de trabalho de cada plantão do serviço, sendo um no período da manhã, outro à tarde e um grupo com cada plantão noturno, na tentativa de contemplar o maior número de profissionais possível de todos os turnos, totalizando 34 participantes.

Os grupos tiveram a duração média de 50 minutos e os moderadores das discussões foram à pesquisadora principal e a sua orientadora, a co-autora da pesquisa. Todas as reuniões foram gravadas e transcritas na íntegra, utilizando-se a técnica de análise hermenêutica-dialética, levando o intérprete a compreender o texto e o processo de conhecimento sob um olhar de múltiplas determinações, considerando o contexto histórico e social ${ }^{(16,20)}$.

Tal análise consistiu em identificar, primeiramente, as idéias; em seguida, identificar os núcleos e, por fim, identificar os temas de cada grupo focal. Os temas de cada grupo foram, então, reunidos em grandes temas para discussão(20).

De acordo com a Resolução 466/2012, do Conselho Nacional de Saúde (CNS) e de acordo com a Norma Operacional $n^{\circ}$ 001/2013, a pesquisa foi submetida ao Comitê de Ética em Pesquisa (CEP), da referida instituição de ensino, obtendo aprovação com número parecer $n^{\circ} 1.377 .805$. 


\section{RESULTADOS E DISCUSSÃO}

\section{Etapa 1 - As necessidades dos pacientes no perioperatório}

Considerando a caracterização dos 26 entrevistados participantes, $58 \%$ eram homens, $38 \%$ tinham idade entre 41 e 60 anos, $42 \%$ eram casados e 54\% relataram ter alcançado o nível de Ensino Fundamental incompleto. Sobre a religião, $58 \%$ eram católicos e $4 \%$ afirmaram não seguir uma religião. Sobre a especialidade cirúrgica, $31 \%$ tinham sido submetidos a procedimento ortopédico e outros $31 \%$ a cirurgia geral. A partir da análise das entrevistas, emergiram dois discursos, apresentados a seguir.

\section{Ideia Central A - Presença de orientações superficiais no perioperatório que pouco se relacionam com as necessidades do paciente.}

"Ninguém explicou nada. Escutei ele falar com os meninos que estudam cirurgia que ia ter que operar. 0 médico só chegou para mim e falou: a gente vai te abrir, se tiver que tirar a gente tira; senão, fecha de novo. Eu falei que 'tudo bem', queria só que tirasse logo minha dor!. Lá no centro cirúrgico, o anestesista fez umas perguntas para mim... Se eu tinha alergia, se eu tomava algum remédio, se eu tinha alguma doença, se já tinha feito alguma operação... Fez exame de sangue para ver se podia operar. Eles conversaram comigo depois da cirurgia, mas só bate-papo mesmo para descontrair. Eu que tinha que ficar atrás... Chega uma hora que cansa de perguntar, porque falar da cirurgia eles não falam não." (DSC A)

No discurso podemos perceber que as informações fornecidas ao paciente e à família, no perioperatório, são superficiais ou pontuais, sendo voltadas ao modelo tradicional de educação em saúde, sem nenhum tipo de aprofundamento. Portanto, como uma conversa informal, torna-se impossível a criação de vínculo e a corresponsabilização do cuidado. Além dessas circunstâncias, no momento da cirurgia, o paciente caracteriza o médico como detentor do conhecimento, uma vez que é esse profissional que detém a responsabilidade sobre o seu corpo, sujeito a cirurgia ${ }^{(5,7,21)}$.

O fato do paciente não compreender seu processo de cuidado, no perioperatório, é reflexo da postura prescritiva e biologicista dos profissionais de saúde. Acresce dizer que o conceito prático de educação em saúde seja de tipo bancário, indo na contramão dos processos ativos de aprendizagem do adulto. De forma ilustrada, a fala dos participantes nos remete à escassez do uso da educação em saúde no cotidiano de trabalho e à fragilidade na comunicação e vínculo entre sujeito e profissional| ${ }^{(3,21)}$.

Sendo assim colocado, o paciente não encontra subsídios para garantir a sua autonomia de participar da tomada de decisão, impondo-se-lhe uma postura de passividade que se estende desde a hospitalização até após a sua "alta". Nessa base, pode até mesmo ficar comprometida a recuperação e a promoção de saúde. Portanto, é necessário que os profissionais de saúde privilegiem sentimentos e valores das pessoas atendidas e de seus familiares, com base no diálogo, estimulando a reflexão em conjunto para as tomadas de decisões, democratizando as relações e, assim, resgatando a humanização(6).

Todavia, toda a pessoa, apesar de autônoma, não é independente. Essa condição decorre de se adoecer e se precisar do cuidado dos outros, seja na forma de tecnologia leve ou dura. Autonomia, nesse caso, significa fortalecer a relação entre pacientes e profissionais da saúde, essencial para a promoção da assistência integral. Por conseguinte, as informações que forem fornecidas à pessoa atendida, no perioperatório, não devem ser aquelas que o profissional julga serem importantes, mas sim centradas nas necessidades individuais de cada paciente, buscando a relação dialógica entre os atores desse processo ${ }^{(22)}$.

Quando a postura de doente é tornada passiva, também pode ser encontrada no momento dos cuidados póscirurgia. Nessa fase, o paciente tem o interesse de compreender melhor seu estado de saúde, bem como o momento vivenciado, mostrando uma possível busca de certo grau de autonomia. Entretanto, ele busca por informações que não são fornecidas. Dessa forma, compreendemos que o cuidado perioperatório, nessa situação, encontra-se centrado em procedimentos, pouco considerando a tecnologia leve para a assistência ${ }^{(15)}$.

Ideia Central B - Ambiguidade de sentimentos e o auxílio da família e espiritualidade no processo de enfrentamento.

"Eu estava sossegado, tinha que fazer isso mesmo. No centro cirúrgico, eu peço bastante para Maria e para o Espírito Santo me ajudar: primeiro Deus, depois as mãos dos médicos. Aí eu vou dormir para não ficar ansioso, porque depois que você tomar anestesia acabou. Deus e minha família me ajudaram." (DSC B) 
Os participantes verbalizam tranquilidade, com relação ao período que antecede a cirurgia. Relatam o fato do procedimento ser algo inevitável. Todavia, é possível identificar no discurso certa ambiguidade de sentimentos, quando há a manifestação da necessidade de não estar acordado, durante a cirurgia, para o entrevistado não ficar ansioso, uma vez que há um processo de cuidado pouco compreendido.

No pré-operatório, tal ambiguidade de sentimentos é recorrente, já que a indicação cirúrgica possui um caráter limítrofe entre representar riscos para a vida e solucionar/amenizar o sofrimento. Certo nível de ansiedade pode ser considerado desejável para impulsionar o paciente a agir e a enfrentar o período peri-operatório. Porém, ele deve compreender e sentir-se suficientemente seguro e confiante com relação à terapêutica, minimizando possíveis complicações, ocasionadas pelo alto nível de estresse ${ }^{(23)}$.

Uma outra possibilidade que poderia explicar a ambiguidade de sentimentos é o fato de a entrevista ter sido realizada na fase pós-operatória, quando o paciente já vivenciou o procedimento cirúrgico e não apresentou complicações ou algum tipo de intercorrência.

Para realizar o enfrentamento do momento vivenciado, o paciente no peri-operatório refere a família como conforto e auxílio. Tanto a família como outro acompanhante com quem a pessoa hospitalizada se sinta acolhida e segura, devem considerar-se na assistência. O motivo para essa posição é a família (ou outro significativo) poder ser aliada no processo de cuidado, potencializando a recuperação do paciente. É importante, portanto, que a equipe de saúde inclua de maneira efetiva a família/acompanhante no cuidado, porém, sem comprometer a autonomia do paciente ${ }^{(24)}$.

Uma vez que não encontram apoio na equipe de saúde, devido à fragilidade no estabelecimento de vínculo, buscam o apoio na família. Os participantes também relatam de maneira enfática a busca por auxílio à espiritualidade. Pedem ajuda espiritual para si e para a equipe médica, a quem entregam seu tratamento ${ }^{(15)}$.

Entende-se por espiritualidade a busca pessoal por significado e sentido maior no existir e sua relação com o sagrado e o transcendente. Essa busca reflete-se em seus ideais e pode estar vinculada (ou não) a uma religião formalizada. Esse envolvimento espiritual está favoravelmente associado a indicadores de bem-estar psicológico, incluindo a satisfação na vida, a felicidade e menor frequência de depressão ${ }^{(23,25)}$.

O cuidado espiritual pode assim promover uma maximização de potencialidades, valorizando as capacidades do paciente, renovando as esperanças e trazendo-lhe a paz interior. Com esse sentimento, lidam com o perioperatório de modo menos estressante ${ }^{(25,26)}$.

Por esse fator, é importante que a equipe esteja atenta às demandas do paciente e aos processos de apoio que ele constrói para vivenciar o momento(27). O olhar profissional pode respeitar a condição do ser humano do ponto de vista integral. Considera-se esse respeito cientificamente terapêutico e livre de preconceitos ou tabus. As perguntas acerca das práticas e crenças espirituais não ofenderão os pacientes, se feitas de forma sensível e respeitosa. Com essa atitude aumenta a criação de vínculo, pois dará mais significado ao cuidado, uma vez que as questões espirituais, dentro da assistência perioperatória, emergem como demanda explícita no discurso dos pacientes ${ }^{(25,26)}$.

Apesar da pertinência do aspecto espiritual no cuidado, os profissionais de saúde encontram-se pouco preparados para lidar com tais questões, criando uma dissociação entre a prática clínica e a prática espiritual. Esse limitado entendimento deriva da formação em saúde ainda abordar de forma reduzida o tema espiritual, nos cursos de graduação. Todavia, é possível que a equipe se instrumentalize para lidar com tais demandas. Assim como ocorre a capacitação sobre as inovações tecnológicas, pode ser incorporado o domínio da espiritualidade, de forma efetiva no cuidado em saúde ${ }^{(25-27)}$.

\section{Etapa 2 - Reflexões da equipe de saúde nos grupos focais}

Foram realizados quatro grupos focais com os profissionais de saúde, um com cada turno de trabalho da referida unidade de estudo. No período da manhã, o grupo focal foi composto por treze participantes; no plantão da tarde, cinco; no plantão noturno I, nove; e no plantão noturno II, dez integrantes da equipe, incluindo enfermeiros, técnicos de enfermagem, assistente social, psicólogo, médico plantonista, farmacêutico, terapeuta ocupacional e gestores do serviço.

A análise dos discursos nos grupos focais possibilitou a identificação de duas temáticas, apresentadas a seguir. Para garantir o anonimato, as falas dos participantes foram identificadas por números e letras. A letra $\mathrm{P}$ é referente aos participantes e a letra $G$ diz respeito aos grupos focais, ambos sendo seguidos pelos números de ordem.

\section{O processo de trabalho fragmentando e a comunicação ineficaz no perioperatório}

Acerca das relações estabelecidas entre os profissionais de saúde, todos os grupos focais apontaram uma comunicação ineficaz entre a equipe cirúrgica e a equipe multiprofissional do HCIII. O trabalho em saúde foi 
caracterizando como individual e centrado na figura do médico-cirurgião. Todavia, os participantes identificaram uma necessidade de mudanças no processo de trabalho e de cuidado, no sentido de se romper com as relações de poder, por meio do diálogo e da aproximação interprofissional.

"Eu fico aqui [...] pensando na discussão que a gente está tendo e observando que o cuidado desse paciente está totalmente centrado na figura do médico, totalmente... E não existe um cuidado multiprofissional para esse paciente [...]." (P12G1)

“[...] Porque, às vezes, para a gente falar com algum dos médicos... [...] Nossa! Demora um 'tempão' para você saber... Então, às vezes o paciente pergunta alguma coisa para a gente, que a gente não vai saber falar. [...]" (P2G4)

"[...] Eu não sei... de encontrar formas de dividir essa responsabilidade e repensar essa questão de dividir com as equipes mesmo [...]." (P2G3)

Outro aspecto comentado com relação à comunicação foi a maneira como a educação em saúde é realizada entre profissional e paciente, já que muitos profissionais utilizam termos técnicos ao conversar com o paciente e dificultam a compreensão do que foi dito.

[...] Porque muitas vezes o médico ia no quarto, fazia orientação, mas falava em uma terminologia que eles não entendiam. Então, eles não tinha compreensão do que estava sendo falado." (P7G4)

No modelo de cuidado tradicional, a educação em saúde está focada na transmissão de conhecimento, caracterizada pela verticalização das ações sem considerar a singularidade do paciente, reforçando, desse modo, a crença de que o paciente é vazio de conhecimento. No seu processo de cuidado, dificulta-se assim a construção ou alcance de algum grau de autonomia. Podemos observar essa posição no momento em que o paciente afirma ter recebido informações superficiais, ratificando seu papel passivo no processo assistencial perioperatório(21,28).

Todavia, as relações verticalizadas e de limitada autonomia não são exclusivas do contato entre profissional e paciente, sendo reproduzidas em todas as esferas do cuidado, presentes entre os chefes de disciplinas cirúrgicas, desde a reserva de sala operatória, passando entre chefe de disciplina e residente até ter seu desdobramento negativo na assistência ao paciente. Como exemplo desse processo fragmentado, emergiu a situação dos cancelamentos frequentes de cirurgias eletivas, que ocasionam mudanças na lógica de trabalho e provocam estresse em pacientes e equipe.

"A impressão que eu tenho é que [...] é uma briga de poder assim, sabe? [...] Então, eles falam: 'Não! A gente tem que deixar todo mundo em jejum para pressionar o centro cirúrgico para operar [...]." (P1G1)

"O duro é quando a cirurgia do paciente é cancelada cinco vezes seguidas e quem tem que dar a notícia cinco vezes seguidas, que o centro cirúrgico cancelou a cirurgia somos nós [...] E aí onde fica a nossa empatia também? [...] Eu crio um vínculo com esse paciente [...] o coração parte [...]. É um desgaste emocional para a gente muito grande [...]." (P3G3)

Apesar de existir um movimento cada vez maior no caminho da gestão compartilhada, planejamento estratégico e trabalho interdisciplinar, os cenários hospitalares perpetuam-se como serviços burocráticos, refletindo-se essa característica na organização e na produção de trabalho realizado. Os níveis de autoridade, inseridos nas estruturas hierárquicas hospitalares, são "possíveis fontes de distanciamento e conflito entre os trabalhadores, o que pode ocasionar a subversão do trabalho nos hospitais"(29).

Quando o poder é desigual, os profissionais podem desenvolver alienação, baixa motivação, consequente passividade e pouca iniciativa no trabalho, o que representa situações de conflitos latentes que fazem crescer a burocracia e diminuir a qualidade da assistência. Em meio a essa situação, o maior prejudicado é o paciente, que deveria ser o motivo principal de todas as decisões tomadas no serviço(29).

A organização hierarquizada e fragmentada do processo de trabalho dentro da categoria médica foi observada na Unidade I do $\mathrm{HC}(\mathrm{HCl})$, de modo geral, unidade em que está inserido o centro cirúrgico. Essa condição vai na contramão da lógica de cuidado compartilhada e almejada na Unidade III, do Hospital das Clínicas (HCIII), gerando morosidade no serviço e dificultando a compreensão das informações da assistência por todos os atores envolvidos ${ }^{(29,30)}$.

Assim, é importante destacar que, na relação profissional-paciente, o respeito do primeiro à autonomia do segundo é um princípio ético, que reflete a organização do processo de trabalho do serviço e deve representar o respeito 
à dignidade humana em sua essência. Transmite, implicitamente, os conceitos de integralidade e humanização, avançando na concepção de saúde reducionista, que enfoca apenas o processo curativo fisiológico. O conceito de assistência ampliada considera antes a prevenção e a promoção de saúde ${ }^{(8)}$.

A equipe multiprofissional também reconhece que seu papel têm sido exercido de maneira secundária, afirmando que não existe um trabalho articulado entre profissionais visando à qualidade da assistência. Deve-se essa postura, certas vezes, a comunicação ineficaz apenas entre médico e paciente, esperando do profissional médico algumas condutas que poderiam ser estabelecidas em equipe, como ocorre com o movimento de educação em saúde. Sendo assim colocado, há descontinuidade das ações, impossibilitando um trabalho colaborativo e, consequentemente, uma assistência centrada no paciente ${ }^{(29,30)}$.

"Eu acho que o que fica mais forte é a questão da informação [...]. O que mais o paciente sente falta é essa questão da conversa mesmo, no entendimento do que está acontecendo com ele [...] enquanto que às vezes, na correria do dia-a-dia, a gente não se atente a isso. [...] E quanto eles esperam do médico conversas que talvez a gente mesmo possa ter." (P2G3)

"Porque a gente trabalha em uma equipe 'multi', mas é verdade que grande parte das dúvidas dos pacientes a gente mesmo pode estar sanando. A visão que precisa do cirurgião para vir explicar, lógico! Também que se for um procedimento cirúrgico complexo ou algum detalhe tem que ser ele, sim, para estar explicando. Mas eu acho que grande parte das dúvidas a gente também consegue sanar, se a gente tivesse uma escuta mais qualificada daquele paciente [...]." (P4G1)

Contudo, o fato de se reconhecer tal fragilidade mostra que a equipe multiprofissional tem refletido sobre as práticas do cuidado, considerando a relevância do trabalho co-responsável e colaborativo no perioperatório. Todo o profissional pode contribuir e somar dentro desse processo, o que inclui a compreensão do paciente acerca de sua situação e a participação no cuidado, com foco em suas necessidades de saúde ${ }^{(31)}$.

$\mathrm{Na}$ base da assistência centrada no paciente, a prática colaborativa pode ser acompanhada por compartilhamento genuíno do cuidado, com a correspondente corresponsabilização de todos os profissionais envolvidos e a ampliação de práticas das profissões não médicas, requerendo mudanças nas estruturas convencionais de poder ${ }^{(31)}$.

Nessa lógica, o que se percebe nas falas dos participantes é que as ações comunicativas e humanas, devido ao processo de trabalho fragmentado, estão fragilizadas nos contatos entre os próprios integrantes da equipe de saúde e entre equipe e paciente. Esses contatos resultam em uma assistência tecnicista, contribuindo para uma falsa impressão de que os recursos humanos são escassos e causam as dificuldades enfrentadas ${ }^{(32)}$.

“[...] Falta de profissionais, falta de recursos humanos, que aí você quer trabalhar de uma forma humanizada, mas dentro dos seus limites, dentro do seu tempo. E aí, em alguns momentos, que a gente pára para pensar, como no caso de hoje, com essa resposta do discurso [...]" (P1G3)

A superação do movimento curativista e fragmentado adota pilares como a humanização, integralidade, autonomia e escuta qualificada, o que pressupõe rearranjos no processo de trabalho em saúde, principalmente no setor terciário. Todavia, é importante que essa articulação possa abranger as atividades instrumentais, humanas e comunicativas, de acordo com as características de cada serviço, buscando a qualidade crescente das ações em saúde ${ }^{(33)}$.

\section{Espaços de aproximação e reflexão da prática: uma possibilidade de mudança}

Todos os grupos mencionaram a importância de espaços de compartilhamento e discussões, entre HCIII e equipe cirúrgica, para o aprimoramento do trabalho em saúde, mesmo que não acompanhada de alguma nomenclatura. Dessa maneira, percebemos que a concepção de trabalho interprofissional desses trabalhadores converge com os princípios propostos no HCllI de assistência colaborativa, mesmo que essa operacionalização ainda apresente fragilidades.

"Eu acho que precisa desses espaços de reflexão da nossa prática. Então, se a gente não reflete sobre a nossa prática, a gente não tem mudanças. O cuidado lá precisa desses espaços para discutir o cuidado, que está sendo feito aqui [...].É bom vocês verem essa devolutiva dos pacientes, para ver o que eles disseram. A gente precisa ouvir isso [...]." (P1G2)

"Acho que o que a gente falou é bem válido, assim, no sentido de dividir responsabilidades. [...] A gente vê a diferença quando a gente tem, por exemplo, residentes que passam aqui que dividem essa responsabilidade com a gente. [...]" (P2G3) 
A necessidade de aproximação entre os profissionais do HCIII e a equipe cirúrgica também pôde ser constatada na sugestão de participação desses médicos nas reuniões de equipe. Essas reuniões já são realizadas no serviço, apesar dos encontros ainda serem incipientes e reducionistas, quando comparados aos preceitos da EPS.

"Acredito, então, que podia acontecer um revezamento deles, na reunião de equipe. Porque se eles estivessem presentes, eles conseguiriam perceber tudo isso, porque às vezes é uma questão do processo de trabalho que eles estão repetindo o que eles viram, o que eles fizeram e não se dão conta disso. Então, de repensar o processo de trabalho, na reunião de equipe.[...]" (P8G4)

As reuniões de equipe que ocorrem na unidade III do HC efetuam-se semanalmente, durante os turnos da manhã e da tarde e, quinzenalmente, nos turnos da noite. Esses espaços são utilizados pela gestão para repasse de informações à equipe assistencial, para discussões de casos clínicos mais complexos e para discussão de problemas pontuais do cotidiano de trabalho. A metodologia de problematização ainda é pouco utilizada e as reuniões pouco sistematizadas.

A qualificação da atenção à saúde está vinculada a estruturação e a organização dos serviços, processo de trabalho, definição de pessoal para o trabalho e disponibilidade de materiais/equipamentos. Além dessas ligações, há a necessidade cada vez mais expressiva de desenvolvimento contínuo e permanente de ações educativas. Essas iniciativas permitem o progresso integral dos trabalhadores em saúde em um movimento de formação-intervenção, ancorado no trabalho e na problematização da realidade ${ }^{(34,35)}$.

Sabe-se que uma formação capaz de promover mudanças nos serviços deve ser acompanhada pela construção coletiva e compartilhada de processos no cotidiano das organizações, articulando a formação, o trabalho, a intervenção e a cogestão. Nessa perspectiva, a Educação Permanente em Saúde (EPS) apresenta-se como uma potente estratégia para reflexão e para transformação dos processos de trabalho, por meio de articulação de saberes de gestores, trabalhadores e pacientes, corresponsabilizando os atores envolvidos no processo para a melhoria na atenção à saúde perioperatória( ${ }^{(13,34,35)}$.

Embora o presente estudo tenha sido realizado em um serviço específico do interior de São Paulo, acreditamos que os resultados suprarreferidos não estão circunscritos à nossa realidade. Refletem o processo de trabalho fragmentado presente nas instituições de saúde públicas e privadas. Entendemos que esse panorama pode-se constituir como disparador para reflexões sobre a lógica vigente da assistência e da gestão dos serviços, principalmente na atenção terciária, tornando explícitas algumas dificuldades a serem superadas. Subsidiam transformações no contexto do SUS, a partir da educação permanente e seus desdobramentos.

\section{CONSIDERAÇÕES FINAIS}

No período perioperatório, os pacientes buscam alcançar informações sobre o momento vivenciado, mas são orientados pelos profissionais de saúde de modo dito como superficial. Apresentam, nesse processo, uma busca por autonomia, mesmo que ainda seja incipiente. Todavia, o modelo de educação em saúde tradicional, presente no cotidiano do serviço, não permite que sejam estimuladas e desenvolvidas a autonomia e a coparticipação da assistência nas relações de cuidado.

Nessa fase considerada a equipe caracteriza o trabalho em saúde como pouco articulado e aponta a comunicação ineficaz como dificuldade para realização de um cuidado integral e humanizado. Como proposta de mudança há a necessidade de inserir a equipe cirúrgica de forma mais efetiva no processo de trabalho do referido local de estudo.

A fim de superar o modelo curativista e fragmentado, o trabalho colaborativo e a tecnologia leve destacam-se como aspectos relevantes, tanto para o cuidado como para a gestão dos serviços. Torna-se necessário investir em espaços de educação permanente dentro dos cotidianos de trabalho, para a constante reflexão e a reconstrução das práticas em saúde. Neste estudo, ressalta que a educação permanente permitiu o olhar de cada profissional para seu microespaço de trabalho, provocando reflexões acerca das ações e das relações entre os atores, podendo refletir em rearranjos a nível organizacional.

Por conseguinte, a educação permanente em saúde tem a potencialidade de agir efetivamente nos processos de trabalho de modo crítico e subsidiar mudanças positivas na lógica de organização dos serviços, com vistas à integralidade do cuidado e das práticas colaborativas. Logo, centrando a assistência nas necessidades do paciente, passa a caracterizar-se a transformação das práticas em saúde, como uma crescente demanda no SUS.

É importante destacar também a pertinência das avaliações sistemáticas, ao longo desse processo da educação permanente, com a finalidade de direcionar metas e intervenções, bem como tornar claros os resultados alcançados e monitorar seus impactos. 


\section{CONFLITOS DE INTERESSE}

Não houve conflito de interesse.

Manuscrito extraído da dissertação de Mestrado "Um olhar para o perioperatório: reflexões da equipe acerca das necessidades do paciente". Faculdade de Medicina de Marília, 2017. 100p.

\section{REFERÊNCIAS}

1. Santos J, Henckmeier L, Benedet SA. O impacto da orientação pré-operatória na recuperação do paciente cirúrgico. Enferm Foco. 2011;2(3):184-87.

2. Pinar G, Kurt A, Gungor T. The efficacy of preoperative instruction in reducing anxiety following gyneoncological surgery: a case control study. World J Surg Oncol. 2011;9(38):1-8.

3. Rigon AG, Neves ET. Educação em saúde e a atuação de enfermagem no contexto de unidades de internação hospitalar: o que tem sido ou há para ser dito?. Texto \& Contexto Enferm. 2011; 20(4):812-7.

4. King J, Chamberland P, Rawji A, Ager A, Léger R, Michaels R, Poitras R, Skelton D, Warren M. Patient educational needs of patients undergoing surgery for lung cancer. J Canc Educ. 2014;29(4):802-7.

5. Watson DS. The benefits of enhanced recovery pathways in perioperative care. AORN Journal. 2015;102(5):46467.

6. Cecílio LCO. As necessidades de saúde como conceito estruturante na luta pela integralidade e equidade na atenção em saúde. In: Pinheiro R, Mattos RA, organizadores. Os sentidos da integralidade na atenção e no cuidado à saúde [Internet]. Rio de Janeiro: IMS/UERJ/ABRASCO; 2001. p.113-26 [citado 10 mar 2017]. Disponível em: http://www.uff.br/pgs2/textos/Integralidade_e_Equidade_na_Atencao_a_saide_-_Prof_Dr_Luiz_Cecilio.pdf.

7. Garret HJ. Effective perioperative communication to enhance patient care. AORN Journal. 2016;104(2):111-20.

8. Raimundo JS, Cadete MMM. Escuta qualificada e gestão social entre os profissionais de saúde. Acta Paul Enferm. 2012;25(esp. 2):61-7.

9. Salci MA, Maceno P, Rozza SG, Silva DMGV, Boehs AE, Heidemann ITSB. Educação em saúde e suas perspectivas teóricas: algumas reflexões. Texto \& Contexto Enferm. 2013;22(1): 224-30.

10. Selimen D, Andsoy II. The importance of a holistic approach during the perioperative period. AORN Journal. 2011;93(4):482-90.

11. Merhy EE, Cecílio LCO. A integralidade do cuidado como eixo da gestão hospitalar [Internet]. Campinas; 2003. [citado 10 mar 2017]. Disponível em: http://ltc-ead.nutes.ufrj.br/constructore/objetos/A\%20INTEGRALIDADE\%20 DO\%20CUIDADO\%20COMO\%20EIXO\%20DA\%20GEST\%c3O\%20HOSPITALAR.pdf.

12. Silva DC, Alvim NAT, Figueiredo PA. Tecnologias leves em saúde e sua relação com o cuidado de enfermagem hospitalar. Esc Anna Nery Rev Enferm. 2008;12(2): 291-8.

13. Vasconcelos MFF, Nicolotti CA, Silva JF, Pereira SMLR. Entre políticas (EPS - Educação Permanente em Saúde e PNH - Política Nacional de Humanização): por um modo de formar no/para o Sistema Único de Saúde (SUS). Interface Comun Saúde Educ. 2016;20(59):981-91.

14. Peres C, Silva RF, Barba PCSD. Desafios e potencialidades do processo de educação permanente em saúde. Trab Educ Saúde. 2016;14(3):783-801.

15. Mazzi NR, Tonhom SFR. O processo de trabalho no perioperatório: reflexões a partir do Discurso do Sujeito Coletivo. In: Anais $6^{\circ}$ Congresso Íbero-Americano em Investigação Qualitativa; $12-14$ jul 2017; Salamanca, Espanha; 2017. p. 210-19.

16. Minayo MCS. O desafio do conhecimento: pesquisa qualitativa em saúde. 13a ed. São Paulo: Hucitec; 2013.

17. Fontanella BJB, Luchesi BM, Saidel GB, Ricas J, Turato ER, Melo DG. Amostragem em pesquisas qualitativas: proposta de procedimentos para constatar saturação teórica. Cad Saúde Pública. 2011;27(2):388-94.

18. Lefevre F, Lefevre AMC. Pesquisa de representação social: um enfoque qualiquantitativo: metodologia do Discurso do Sujeito Coletivo. 2a ed. Brasília: Liber Livro; 2012. 
19. Moscovici S. Representações Sociais: investigações em psicologia social. 11a ed. Petrópolis: Vozes; 2015.

20. Campos DA, Rodrigues J, Moretti-Pires RO. Pesquisa em saúde coletiva como instrumento de transformação social: uma proposta fundamentada no pensamento hermenêutico-dialético. Saúde Transform Soc. 2012;3(4):1424.

21. Guerreiro EM, Rodrigues DP, Queiroz ABA, Ferreira MA. Educação em saúde no ciclo gravídico-puerperal: sentidos atribuídos por puérperas. Rev Bras Enferm. 2014;76(1):13-21.

22. Sayin Y, Güler A. The nurse's role in providing information to surgical patients and family members in Turkey: a descriptive study. AORN Journal. 2012;95(6):772-87.

23. Camponogara S, Soares SGA, Silveira M, Viero CB, Barros CS, Cielo C. Percepção de pacientes sobre o período pré-operatório de cirurgia cardíaca. REME Rev Min Enferm. 2012;16(3): 382-90.

24. Austin EA. Personalized care for families of perioperative patients. AORN Journal. 2016;103(3):13-4.

25. Dal-Farra RA, Geremia C. Educação em saúde e espiritualidade: proposições metodológicas. Rev Bras Educ Med. 2010;34(4):587-97.

26. Koening HG.Religion, spirituality and medicine: research findings and implications for clinical practice. South Med J. 2004;97(12):194-200.

27. Murakami R, Campos CJG. Religião e saúde mental: desafio de integrar a religiosidade ao cuidado com o paciente. Rev Bras Enferm. 2012;65(2):361-7.

28. Fernandes MCP, Backes VMS. Educação em saúde: perspectivas de uma equipe da Estratégia de Saúde da Família sob a óptica de Paulo Freire. Rev Bras Enferm. 2010;63(4):567-73.

29. Vaghetti HH, Padilha MICS, Lunardi Filho WD, Lunardi VL, Costa CFS. Significados das hierarquias no trabalho em hospitais públicos brasileiros a partir de estudos empíricos. Acta Paul Enferm. 2011;24(1):87-93.

30. Souza GC, Peduzzi M, Silva JAM, Carvalho BG. Trabalho em equipe de enfermagem: circunscrito à profissão ou colaboração interprofissional?. Rev Esc Enferm USP. 2016;50(4):640-7.

31. Agreli HF, Peduzzi M, Silva MC. Atenção centrada no paciente na prática interprofissional colaborativa. Interface Com Saúde Educ. 2016;20(59): 905-16.

32. Cecilio LCO, Merhy EE. A integralidade do cuidado como eixo da gestão hospitalar. In: Pinheiro R, Mattos RA, organizadores. Construção da integralidade: cotidiano, saberes e práticas em saúde. Rio de Janeiro: IMS/UERJ/ ABRASCO; 2003. p. 197-210.

33. Pirolo SM, Ferraz CA, Gomes R. A integralidade do cuidado e ação comunicativa na prática interprofissional da terapia intensiva. Rev Esc Enferm USP. 2011;45(6): 1396-402.

34. Silva LAA, Schmidt SMS, Noal HC, Signor E, Gomes IEM. Avaliação da educação permanente no processo de trabalho em saúde. Trab Educ Saúde. 2016;14(3):765-81.

35. Gigante RL, Campos GWS. Política de Formação e Educação Permanente em Saúde no Brasil: bases legais e referências teóricas. Trab Educ Saúde. 2016;14(3): 747-63.

\section{Endereço para correspondência:}

Nathália Romeu de Mazzi

Universidade do Oeste Paulista - UNOESTE

Rua José Bongiovani, 920, Campus I

Cidade Universitária

CEP: 19050-920 - Presidente Prudente - SP - Brasil

E-mail: nathaliarmazzi@gmail.com 